\title{
Experimental performance of a solar thermal liquid desiccant air conditioning system $-\mathbf{A}$ review
}

\author{
S. Bouzenada \\ Department of Architecture, University 3 Constantine, 25000, Algeria \\ Corresponding Author: bouzenada_84@yahoo.fr (saliha bouzenada)
}

\begin{abstract}
Solar energy may be the great option to provide the conditioned air in summer, as solar energy available in plenty. Liquid desiccant air conditioning (LDAC) system using solar energy is proposed as an alternative to the conventional vapor compression systems due to its advantage in, removing the air latent load, friendly to environment, removing of pollutants from the process air, reduction of the electrical energy, do not using the harmful refrigerants and protection to ozone layer depletion. In this paper, the recent works on solar driven liquid desiccant air conditioning system and its advantages are reviewed. The system may offer in terms of energy savings are underscored. A basic description of (LDAC) system is provided. The regeneration temperature and solar collector efficiency are developed and the analysis highlights the performance of the system. The literature review has highlighted that there is a clear need for research in the field of liquid desiccant air conditioning system with solar energy in many buildings. This is due to the patent operational advantages the system can deliver in terms of energy saving from 25 to $50 \%$, operating costs and energy security, the low regeneration temperature. The objective of this paper review is to access using of liquid desiccant based air conditioning, regenerated by eco-friendly renewable energy. The liquid desiccant systems present multifunctional properties that make them particularly interesting in several fields of application. Electric utilities have their peak loads in hot summer and are often barely capable of meeting the demand, with brown-out situations. It is a good application for solar energy due to the fact that the greatest demand for air conditioning occurs during times of highest insolation.
\end{abstract}

\section{Key words}

Solar energy, Evaporative air-conditioning system, Liquid desiccant, Vapor compression system.

\section{Introduction}

The growing demand for air conditioning, particularly in hot and humid climates has caused a significant increase in energy resources and this induces global warming throughout the world. The increased emission of $\mathrm{CO}_{2}$ and other greenhouse gases (GHG) will cause many climatic disturbances because of increase in global temperature. The heating, ventilation and air conditioning (HVAC) system consumes more than $40 \%$ of the total energy consumption of the building; and consume about $60 \%$ of the total energy consumption of commercial buildings in the tropical region $[1,2,3]$. Currently, the air conditioning market is dominated by vapor compression systems (VCS). However, VCS make use of harmful refrigerants such as R-410A, materials with high global warming potential and use significant quantities of electrical energy to drive the compressor. Owing to the fact that the most common form of electrical generation in the majority of counties is from the combustion of fossil fuels, VCS can be viewed as neither a sustainable nor efficient air conditioning option [4]. Therefore, it is necessary to find out the ways of reducing overall energy consumption of such power-hungry systems [1]. (LDAC) system represents one of the technologies for heating/cooling, able to be driven by the heat coming from low-temperature renewable energy sources. The HVAC systems results in significant electric and economic savings and from an environmental viewpoint, resulting in lower $\mathrm{CO}_{2}$ emissions [5]. Solar energy may be the great option to provide the conditioned air in summer, as solar energy available in plenty [6]. It is a good application for solar energy due to the fact that the greatest demand for air conditioning occurs during times of highest insulation. Therefore, the LDAC system has been proposed as an alternative method to obtain more energy efficient and a better indoor air quality in buildings [7]. The dehumidifier and regenerator are the main components of a LDAC system. The main role of the desiccant is to attract water vapor from air; and can be regenerated at low temperature, from approximately $50-80{ }^{\circ} \mathrm{C}[8]$. The first liquid desiccant air-conditioning system was developed by Lof [9] in 1955, the system operating with the triethylene glycol solution as the liquid desiccant. The current research include properties of desiccant solution LDAC equipment, such as spray tower, packed bed tower, falling film column; liquid-toair membrane energy exchangers and hybrid system. In these areas, an increasing attention is given to the system performance. Zhang and Zhang [10] analyzed the system performance under varying operating conditions (air flow rate, fresh air temperature and liquid desiccant flow rate). Abdel-Salam and Simonson [11] studied the sensitivity of the moisture removal rate, COP system and capacity matching index to the six designs and operating parameters. Based on the experiments, Sheridan [12] 
prepared a Lithium Bromide solution with a temperature in the range of $70-85^{\circ} \mathrm{C}$. Mehta [13] demonstrated the liquid desiccant based air-conditioning system to reduce the consumption of energy. Author has demonstrated regeneration of this system using solar thermal collector along with integrated liquid desiccant heat exchanger. Further, author has also demonstrated regeneration using waste heat and dehumidification of air in an internally cooled liquid desiccant - air contacting device. Su et al. [14] proposed a novel liquid desiccant system integrated with concentrated photovoltaic/thermal collector for the dehumidification. They have stated that heat released from the collector can be used for the regeneration of desiccant. Kabeel et al. [15] have numerically investigated the solar energy assisted desiccants wheel based air-conditioning system for the condition of Cairo. They have investigated the configuration of system with three different heat sources such as electrical energy, solar energy and thermal storage tank filled with phase change material. Authors have concluded that solar energy and thermal storage tank has a potential to save the electrical energy. Keniar et al. [16] investigated the feasibility of using a solar regenerated liquid desiccant membrane system to remove humidity from an office space and the result shows that a payback period of 7 years was estimated compared to the investment in the vapor compression cycle. Armanasco et al. [17] used available heat driven cooling technologies in combination with solar thermal collectors to reduce the load caused by air conditioning on the electric utilities and to reduce the environmental impact, and experimental tests run during summer showed average primary energy saving index of $30 \%$. Islam [3] presented a simple theoretical model to quantify the heat and mass transfer rates ; an energy saving of up to $25 \%$ can be achieved using the hybrid air-conditioning systems.

The idea of a LDAC system is to combine liquid desiccant dehumidification with an evaporative cooling system in order to advance the overall system performance and use solar energy as a clean, renewable energy resource. Further, as only low-grade energy is required for the regeneration process of the desiccant, solar energy can handle running liquid desiccant air conditioning system.

Desiccant dehumidification is a technology that has been in use long time ago for both industrial and agricultural purposes including humidity control in textile mill and post-harvest crop drying in stores. In the recent years, a large body of research has been concentrated on desiccant materials and their applications in various fields especially dehumidification and cooling applications. This is based on the reliability and simplicity provided by desiccant dehumidification and cooling systems and the desiccant materials ability to be regenerated with low temperature heat, solar energy, biomass heat, or any waste heat source. Such systems do not use ozone depleting fluids and can independently control temperature and humidity in a conditioned space.

It is reported that desiccant-based dehumidification unit use less than a quarter of the energy compared to traditional vapor compression systems. On the other hand, liquid desiccant based dehumidification is a relatively new technology compared to solid desiccant systems employing a deliquescent material to absorb moisture from air, including lithium chloride ( $\mathrm{LiCl})$ and calcium chloride $\left(\mathrm{CaCl}_{2}\right)$. Compared to solid desiccants, liquid desiccant-based systems have higher utilization flexibility and mobility, lower regeneration temperature, and capability of absorbing pollutants and bacteria.

The air handling in air conditioning systems was moist because of the dehumidification process in summer, so bacteria were easily propagated and developed. In addition, the air humidity in moist central air conditioning systems is seldom controlled. Solar energy driven liquid desiccant cooling air conditioning systems can improve indoor air quality and reduce electrical energy consumption and have been regarded highly by researchers and engineers in recent years. The desiccant based air conditioning system comes to be one of the prospective alternatives for the traditional vapor compression air conditioning systems.

Scientists and engineers are trying to develop more efficient air conditioning systems that are capable of achieving good indoor air quality with low energy consumption rates and air pollution emissions. The application of the system can be in institutional and residential buildings, such as schools, colleges, universities, libraries, hospitals, museums, indoor stadium, cinema theatres, hotels...etc; also, in commercial buildings, such as offices, shopping centers, supermarkets, restaurants and other [18].

The objective of this study is to present a literature review over the recent developments on solar assisted liquid desiccant air conditioning systems using solar energy, and the comparison between traditional vapor compression systems. The review is to access using of liquid desiccant based air conditioning, regenerated by eco-friendly solar energy.

\section{Liquid desiccant air conditioning system}

A solar liquid desiccant air conditioning system is shown in Fig. 1. It is a thermally driven open cooling cycle based on evaporative cooling and absorption. A (LDAC) system has three main components namely the regenerator, dehumidifier and solar collector. It also comprises a hot water storage tank, a hot water circulation pump, a heat exchanger located in the solution tank for the purpose of heating the dilute solution before the regeneration process and air fan on the process air side. In addition, there are two solution pumps for circulating the rich and the poor solution. Solar energy is popularly used as liquid desiccant regeneration temperature is usually under $80^{\circ} \mathrm{C}$, which can be conveniently collected from the sun energy. In liquid desiccant based air conditioning system, air is cooled in dehumidifier and diluted solution concentrated in regenerator. Fig. 1 shows a simple schematic of LDAC system containing a dehumidifier, a regenerator and solar collector. Moisture from the inlet air is removed in the dehumidification or absorber unit, where the desiccant absorbs the water vapor from the process air. Mass transfer takes place due to the difference in vapor pressure. The diluted desiccant is pumped back to the regenerator. Before the diluted solution enters the regenerator, it is initially passed through a liquid-liquid 
sensible heat exchanger and then a heating coil, where its temperature is raised. In the regenerator, the hot diluted solution is exposed to regenerative air, and moisture is transferred from the weak solution to air due to the difference in vapor pressure. This concentrated solution

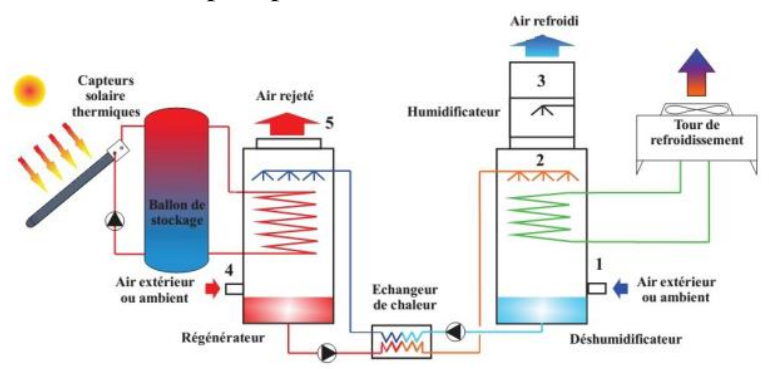

Fig. 1. Liquid Desiccant Cooling System [ANIES, 19]

again passes through a liquid-liquid heat exchanger and it enters the dehumidification unit. This heat exchanger is used to pre-heat the weak solution and pre-cool the strong solution. After the regeneration process, the liquid desiccant solution becomes concentrated. Before being sprayed into the process air again to complete the cycle, the liquid desiccant solution is cooled by a cooling tower to adjust the temperature to the desired level. The capability of a desiccant material to absorb moisture is governed by its equilibrium vapor pressure [18].

A liquid desiccant dehumidification system consists of two major sub-units, a dehumidifier and a regenerator as presented in Fig. 2. In the dehumidifier, strong liquid desiccant absorbs moisture to dehumidify the hot and humid process air due to the difference in the water vapor pressure between the air and the desiccant surface.

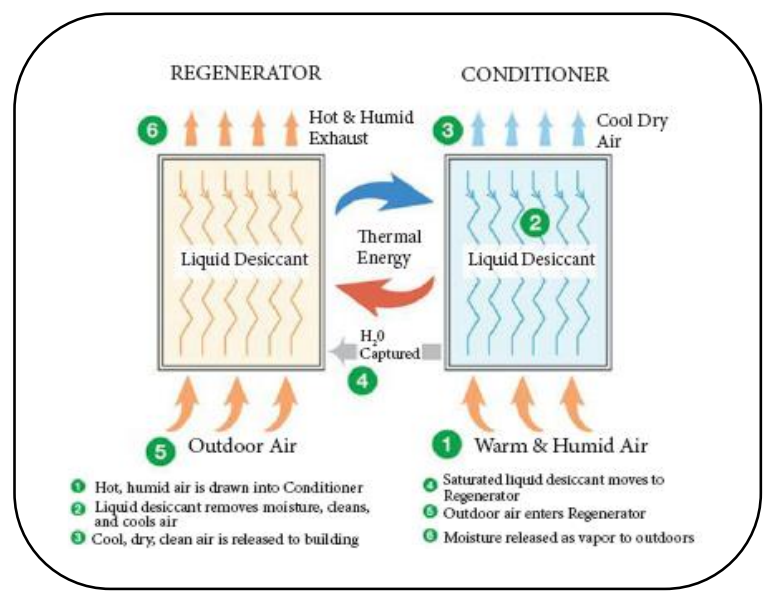

Fig. 2. Liquid desiccant dehumidification system operation

Therefore, the liquid desiccant concentration decreases and its moisture content increases to become saturated, where the air is dehumidified and its moisture content decreases. To allow a continuous operation of the liquid desiccant dehumidification unit, the weak liquid desiccant is transferred to the regenerator where it is re-concentrated, reducing its moisture content by means of an external heating source such as solar energy. In the case of falling film absorber/regenerator, the strong desiccant flows down along the falling film and is soaked and held firmly by the long fiber having favorable hydrophilic properties and strong water absorptivity. Thus, humid air flows between the plates to get in contact with the liquid desiccant falling film on the different plates without carrying out the desiccant droplets. As the humid air gets in direct contact with the liquid desiccant film, the water vapor pressure difference between the surface of the desiccant film and the process air allows moisture absorption by the strong liquid desiccant solution. This vapor pressure difference represents the driving force of the mass transfer. In addition, the relatively lower temperature of the liquid desiccant film allows sensible cooling of the process air and both the sensible heat and the latent heat of condensation are transferred from the air side to the relatively cold desiccant solution. The regeneration core allows reducing the moisture content of the liquid desiccant through heating the solution and transferring the moisture to the regenerator process air, in order to reconcentrate the desiccant solution and reuse it in the cycle [18]. Liquid desiccants are solutions that have a high affinity for water vapor. This property is the key to creating cooling systems that dehumidify air without over-cooling. The liquid desiccants used in these systems commonly are very strong solutions of the ionic salts lithium chloride, lithium bromide and calcium chloride. These ionic salts have the attractive characteristic [19].

Many investigations have been dealing with experimental testing and modeling on solid desiccant air conditioning system but few studies have been carried out on system using liquid desiccant for solar cooling applications. The earliest liquid desiccant system was suggested and experimentally tested by Löf [9]. Elhelw [20] studied a solar liquid desiccant air conditioning system. The effect of changing evacuated tube collector area on the performance of the system was fulfillment. Then, the hourly differences of different parameters were calculated. In addition, the maximum solar thermal energy was determined to meet the regeneration demand according to the hourly average solar radiation data. For $220 \mathrm{~m}^{2}$ evacuated tube collector area, the maximum required heat energy is obtained as $38.286 \mathrm{kWh}$, while using solar energy, will save energy by $30.28 \%$ annual value. About a COP it is seen that increasing solar collector area will increase the regenerator thermal COP because of increasing the enthalpy of the water desorbed through regenerator, and the amount of heat absorbed in the regenerator. The thermal COP of this system has reached a value range from 0.75 to 0.83 .

Recently, liquid desiccant systems have been implemented on the commercial level in conjunction with evaporative coolers and have recorded energy savings upwards of 50\%. Joel [21] carried out a study on a low cost solar liquid desiccant system for residential cooling. The aim of this research is to test the potential liquid desiccant system on the residential level when paired with a conventional vapor compression cycle and to construct a system that would overcome some of its barriers to the residential market. The liquid desiccant system achieved a maximum energy savings of $38 \%$ over a complete day and $52 \%$ over a single cooling cycle. It was projected that the system has the potential to save $1064 \mathrm{kWh}$ over the course of a year. When combined with a renewable source of heat for regeneration, liquid desiccant systems become very cost effective. This 
research provides evidence of the technology's potential on the residential sector and suggests ways for it to become competitive in the market.

Zhipeng [22] presented a study on hybrid liquid desiccant cooling system and a conventional vapor compression system of air conditioning. The study focuses on coefficient of performance of these two systems. Results from the experimental study of the conventional air conditioning cooling load and COP relationship process are depicted graphically in Fig. 3. This figure shows that when outdoor temperature increases, the cooling load will increase from $12.3 \mathrm{kw}$ to $15.98 \mathrm{kw}$. During the same time period, the whole system COP decreases from 5.0 to 2.5. This indicates that when the outdoor temperature is high, cooling load will also increase. The conventional system COP will therefore be reduced.

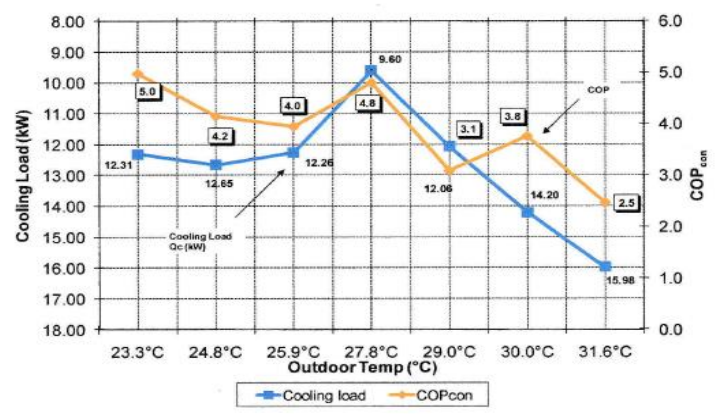

Fig.3. Conventional air conditioning cooling load and COP

In similarity to $\mathrm{COP}$, the hybrid liquid desiccant cooling system ECOP can be described graphically and is shown in Fig. 4. For example, when the low outdoor temperature is $23.3^{\circ} \mathrm{C}$, it can be seen that the cooling load approximates to $7.5 \mathrm{kw}$. The ECOP rises from 4.8 to 6.7 but the total trend ECOP is decreasing as the cooling load has increased. Therefore, when the cooling load increases to $8.08 \mathrm{kw}$, ECOP should be decreased to a low level; it can be found that minimum decreasing to 5.3.

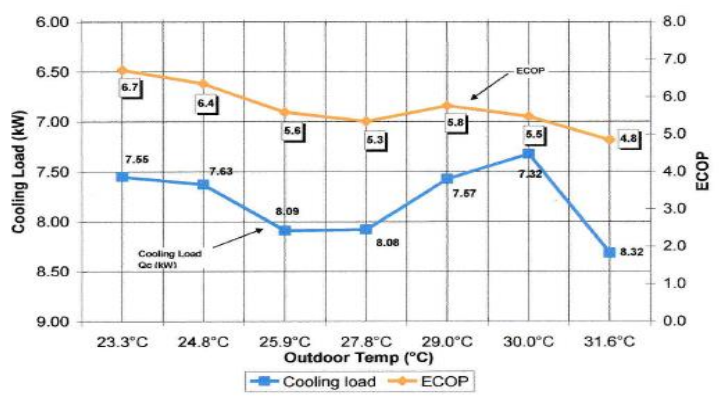

Fig.4. Hybrid air conditioning cooling load and ECOP relationship

Also, a comparison on hybrid system with and without solar energy has been made. It can be seen on Fig. 5 that the changes of $\mathrm{COP}_{\text {sys }}$ depend on ECOP and TCOP variation. Due to the solar energy being a free energy input, when the hybrid system uses solar energy to regenerate liquid desiccant section, the whole system $\mathrm{COP}_{\text {sys }}$ becomes greater by changing value from 4.6 to 6.2. On the other hand, if the hybrid system does not use solar energy and electricity is selected to work as inlet heating energy, the whole system $\mathrm{COP}_{\text {sys }}$ decreases to 1.4. In this figure, the hybrid cooling system $\mathrm{COP}_{\text {sys }}$ (using solar energy) and ECOP approximate parallel lines. At the bottom of this figure, a similar characteristic can be viewed with the hybrid cooling system $\mathrm{COP}_{\text {sys }}$ (not use solar energy) and TCOP approximate parallel relationship.

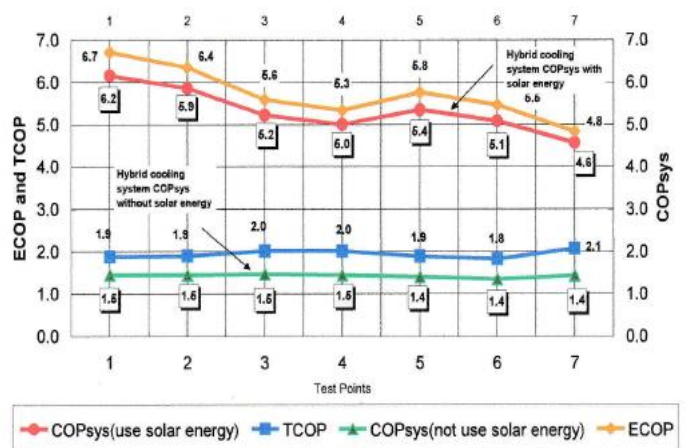

Fig.5. Hybrid cooling system TCOP, ECOP, and COP system

The performance difference between $\mathrm{COP}_{\text {sys }}$ (using solar energy) and ECOP changes in value from 0.2 to 0.5 . At the same time, $\mathrm{COP}_{\text {sys }}$ (not using solar energy) and ECOP difference varies from 0.4 to 0.7 . This means that when the system use solar energy, thermal energy input can be calculated as free. The analysis of the comparison between the conventional system and hybrid system demonstrates that the conventional cooling system, using a vapor compression system to deal with sensible and latent heat load both had a performance COPcon variation ranging from 5.0 to 2.5 . The overall COP of the hybrid liquid desiccant cooling systems predicted by calculation ranges from 6.2 to 4.6 when system uses solar energy, or 1.5 to 1.4 without use solar energy. These have shown a much better savings in a desiccant dehumidifier with solar energy using.

The regeneration temperature affects the performance of desiccant cooling system, using liquid or solid material as shown in Fig.6 (a) the performance parameters for the
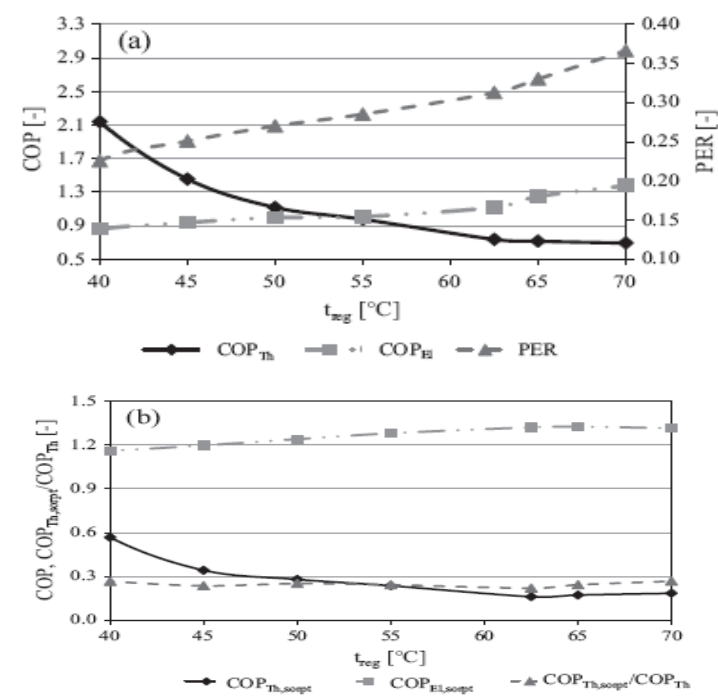

Fig.6. Performance parameters

overall DCS and Fig.6(b) for the desiccant rotor. As process and regeneration air flow rates are constant, the increase of $\mathrm{T}_{\text {reg }}$ determines a strong reduction of $\mathrm{COP}_{\mathrm{Th}}$, from 2.1 to 0.7 when regeneration temperature increases 
from 40 to $70^{\circ} \mathrm{C}$. The adoption of low temperatures, however, determines low moisture removal capacity and dehumidification effectiveness of the desiccant wheel. Saving Energy is one of the main concerns in the desiccant cooling system. The energy analysis results suggest a savings of more than $32 \%$ in electric consumption when compared to conventional air system. It was concluded that this system provides significant energy savings.

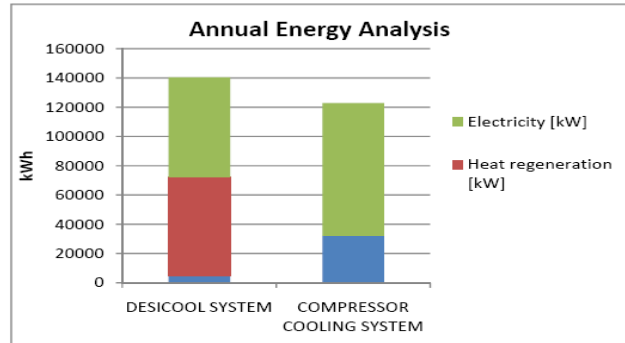

Fig.7. Annual energy between conventional and DC systems

Juan [23] studied a desiccant cooling system and analyzed a saving energy of this system.

It can be seen in Fig.7 that the graph clearly shows that:

- The amount of electricity used is smaller than the used by the compressor cooling system.

- This system uses a considerable smaller amount of heat in the after heating, 4700kwh, and $32100 \mathrm{kwh}$ used by the traditional system.

Other researchers carried out some studies on liquid desiccant air conditioning system and the results show that the analysis based on solar energy and desiccant demonstrated that the performance of the investigated system can increase. Total energy saving ranging from 25 to $50 \%$ was obtained. Some simulation results indicated that solution outlet concentration increases $70 \%$.

An experimental study carried out by Christopher McNevin [24] to evaluate the performance of a novel multi-stage liquid-desiccant air-conditioner. The system presented in Fig.8 was tested at different inlet cooling water temperatures, ranging from $8{ }^{\circ} \mathrm{C}$ to $20{ }^{\circ} \mathrm{C}$, using a solution of $\mathrm{LiBr}$ and water as the desiccant.

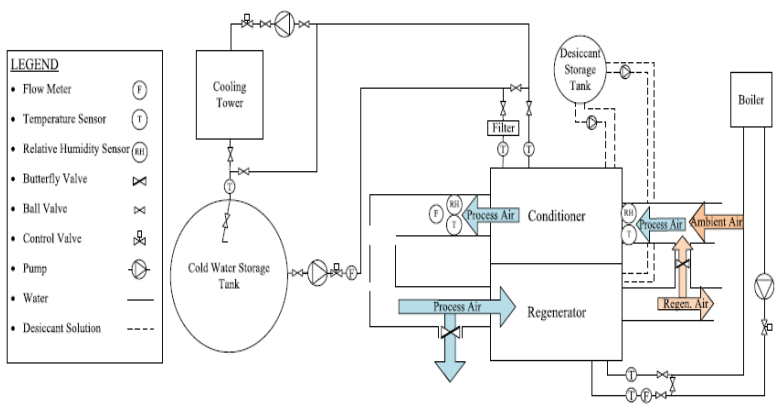

Fig. 8. System Layout showing sensor locations, air flows.

The system was able to provide high sensible cooling rates of up to $8.8 \mathrm{~kW}$. The energy consumption of the system was low, with an average thermal coefficient of performance (COP) of 0.58 and electrical (COP) of 4.7. To aid in future design improvements, a variable effectiveness based TRNSYS model was developed. The use of higher effectiveness desiccant to water heat exchangers was simulated improve COPT to 0.7 .

\section{Liquid desiccant materials}

A desiccant is capable of showing a strong attraction for water vapor. The characteristics of the desiccant material being utilized impact the performance of the desiccant air conditioning systems significantly. One key principle for selecting appropriate desiccant is the water absorption capacity of a desiccant solution. It depends on its equilibrium vapor pressure then, on concentration.

S. Bouzenada [25] has carried out experimental tests at different inlet conditions to study the dehumidification process during air injection thought the desiccant liquid for both the $\mathrm{CaCl}_{2} \cdot 2 \mathrm{H}_{2} \mathrm{O}$ and $\mathrm{MgCl}_{2}$. In the dehumidification experimental presented in Fig. 9 the absolute difference between these solutions, placed under the same climatic conditions with forced air flow is that, the water absorbed by $\mathrm{CaCl}_{2} \cdot 2 \mathrm{H}_{2} \mathrm{O}$ is higher then that absorbed by $\mathrm{MgCl}_{2}$. It can be pointed out that, $\mathrm{CaCl}_{2} \cdot 2 \mathrm{H}_{2} \mathrm{O}$ has a higher capability to absorb moisture from the air than the $\mathrm{MgCl}_{2}$. Therefore, the higher mass transfer potential will be the higher moisture removal rate in the same operating conditions.

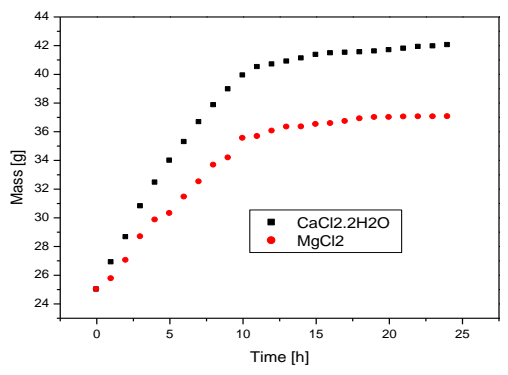

Fig. 9. A comparison of two liquid desiccants

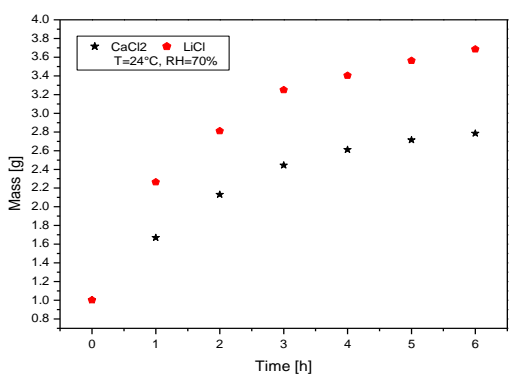

Fig. 10. Mass evolution of $\mathrm{LiCl}$ and $\mathrm{CaCl}_{2}$

S. Bouzenada [26] studies a comparative study on absorption/regeneration is operated in various conditions by using $\mathrm{CaCl}_{2}$ and $\mathrm{LiCl}$ as desiccants. The evaluated parameters are desiccant concentration, vapor pressure of air and water vapor rate absorbed and released by desiccants. Fig. 10 illustrates the evolution of $1 \mathrm{~g}$ of both $\mathrm{LiCl}$ and $\mathrm{CaCl}_{2}$ desiccants during dehumidification at $24^{\circ} \mathrm{C}$ of and $70 \%$ of humidity. As shown in this figure, the mass increases when the $\mathrm{Cacl}_{2}$ and $\mathrm{LiCl}$ absorb moisture from air. The vapor pressure of air decreases this is due to decrease of concentration. It can be pointed out that, $\mathrm{LiCl}$ solution showed much better mass transfer. Indeed, $\mathrm{LiCl}$ solution exhibits better dehumidification than $\mathrm{CaCl}_{2}$. 


\section{Conclusion}

The aim of the review is to highlight the current research of liquid desiccant air conditioning system using solar energy gap regarding a traditional vapor compression system and advantages the system may offer in terms of energy savings are under scored. All literature reviewed has been selected due to its relevance in achieving the central aim of this study. Particular areas the review focuses on are system: design of absorber/regenerator, thermal performance and energy savings. Moreover, solar regeneration method and recent developments are presented. Through the literature it can be pointed out that the favorable features of the liquid desiccant systems over the solid desiccant cooling systems can be summarized as low vapor pressure, low viscosity, low regeneration temperature and ability of absorbing pollutants, high density and being cost effective. Total energy savings rate is ranged from 25 to $50 \%$ in comparison to the vapor compression system. Finally, the use of solar energy for this system is logical as higher availability of solar radiation matches with higher demand for air conditioning in summer.

\section{References}

[1]. G. Fekadu, S. Subudhi. Renewable energy for liquid desiccants air conditioning system: A review. Renewable and Sustainable Energy Reviews 93 (2018) 364-379.

[2]. M. Golam Rasul, C. Doring. Performance assessment of desiccant air conditioning system in an institutional building in subtropical climate. Energy Procedia 110 (2017) 486 491

[3]. M.R. Islam, S.W.L. Alan, K.J. Chua. Studying the heat and mass transfer process of liquid desiccant for dehumidification and cooling. Applied Energy 221 (2018) 334-347.

[4]. T. Elmer, M. Worall, S. Wu, S. Riffat. An experimental study of a novel integrated desiccant airconditioning system for building applications. Energy and Buildings 111 (2016) 434-445.

[5]. A. Giampieri, Z. Ma, A. Smallbone, A. P. Roskilly. Thermodynamics and economics of liquid desiccants for heating, ventilation and air-conditioning - An overview. Applied Energy 220 (2018) 455-479.

[6]. V. Kalpesh, M. Dhruvin, L. Shukla. Regeneration of liquid desiccant for solar air-conditioning and desalination using hybrid solar still. Energy Conversion and Management 171 (2018) 1598-1616.

[7]. X. Ou, W. Cai, X. He, D. Zhai. Experimental investigations on heat and mass transfer performances of a liquid desiccant cooling and dehumidification system. Applied Energy 220 (2018) 164-175.

[8]. A. Th.Mohammad, S. Bin Mat, M.Y. Sulaiman, K. Sopian, A. Al-abidi. Survey of hybrid liquid desiccant air conditioning systems. Renewable and Sustainable Energy Reviews 20 (2013) 186-200.

[9]. Lof GO. Cooling with solar energy. In: Congress on Solar Energy; vol. 2. Tucson (USA); 1955. p. 171-89.

[10].LZ. Zhang, N.A. Zhang. A heat pump driven and hollow fiber membrane-based liquid desiccant air dehumidification system: modeling and experimental. Energy 65 (2014) 44151.

[11].AH. Abdel-Salam, CJ. Simonson. Capacity matching in heat-pump membrane liquid desiccant air conditioning systems. Int J Refrig 48 (2014) 166-77.
[12].NR. Sheridan. Prospects for solar air conditioning in Australia. In: United Nations conference on new sources of energy, Rome; 1961.

[13].JR. Mehta. Demonstration of liquid desiccant based air conditioning system using solar energy and waste heat. Indian J Sci Technol 10; 35 (2017) 1-6.

[14].B. Su, W. Qu, W. Han, H. Jin. Feasibility of a hybrid photovoltaic/thermal and liquid desiccant system for deep dehumidification. E. Convers Manage 163 (2018) 457-67.

[15]. A.E. Kabeel, M. Abdelgaied. Solar energy assisted desiccant air conditioning system with PCM as a thermal storage medium. Renew Energy 122 (2018) 632-42.

[16].K. Keniar, K. Ghali, N. Ghaddar. Study of solar regenerated membrane desiccant system to control humidity and decrease energy consumption in office spaces. Appl Energy 138 (2015) 121-32.

[17].F. Armanasco, C.L. Pietro Maria, A. Lucchini, A. Rossetti. Performance analysis of a solar cooling plant based on a liquid desiccant evaporative cooler. Int J Refrig 53 (2015) 163-76.

[18].M. Jradi1, S. Riffat. Energy performance of an innovative liquid desiccant dehumidification system with a counterflow heat and mass exchanger using potassium formate. ISSN 2052-6237 | Volume 2 | Article 5 (2014). Doi: 10.7243/2052-6237-2-5.

[19].G. Anies. Modélisation, simulation dynamique, validation expérimentale et optimisation énergétique d'une unité de rafraichissement solaire par absorption. Thesis (2011).

[20].M. Elhelw. Performance evaluation for solar liquid desiccant air dehumidification system. Alexandria Engineering Journal 55 (2016) 933-940.

[21].D. Joel. Ware III. A low-cost solar liquid desiccant system for residential cooling. Thesis (2013).

[22].Z. Zhipeng. Performance analysis of hybrid liquid desiccant solar cooling system. Queensland university. $\mathrm{PhD}$ (2009).

[23].U. Juan Artieda. Desiccant Cooling Analysis Simulation software, energy, cost and environmental analysis of desiccant cooling system. Thesis (2010).

[24].C. McNevin, S. J. Harrison. Multi-stage liquid-desiccant air-conditioner: Experimental performance and model development. Building and Environment 114 (2017) 4555 .

[25].S. Bouzenada et al. Experimental investigation on dehumidification comparison of two liquid desiccants. $13^{\text {th }}$ International Conference on Sustainable Energy technologies (SET2014). 25-28th August, 2014. Geneva. Paper ID: SET2014-E10002

[26].S. Bouzenada et al. Experimental comparative study on lithium chloride and calcium chloride desiccants. Procedia Computer Science 83 ( 2016 ) 718 - 725. 